\title{
- OLHA Ô PROGRAMA DA PEÇA!
}

\author{
Felipe Matheus Bachmann Ribeiro e
}

Walter Lima Torres Neto ${ }^{1}$

O programa de teatro moderno, tal como o conhecemos hoje, data de meados do século XIX. Seu provável predecessor foi o cartaz, que tinha por objetivo anunciar um determinado espetáculo. Na contemporaneidade, verificase uma variedade gráfica e conteudística nos programas de teatro. Uma análise de programas brasileiros a partir do ano de 1953 fundamenta uma pequena definição da natureza do programa de teatro, identificando suas diferentes ênfases que configuram uma tipologia de programas e exprimem um novo pacto estético-cultural entre o público e os agentes criativos da cena teatral brasileira contemporânea.

Palavras-chave: Programa de teatro, Paratexto, Teatro brasileiro.

\section{Abstract}

The modern theatre programme comes from the middle of the nineteenth century. Its probable predecessor was the theatre poster, whose aim was to announce a performance.

In the contemporaneity, one observes a variety in both typography and content features of the theatre programmes. An analysis of Brazilian theatre programmes since 1953 lays the foundations for a brief definition of the nature of the theatre programme. It also provides the basis for identifying the different emphases that form the typolgy of programmes and for expressing a new culturalaesthetic pact between the audience and the creative agents of the contemporary Brazilian theatrical context.

Keywords: Theatre programme, Paratext, Brazilian theatre. 
Transcrevo o programa dessa récita, não só para marcar a importância

da sua categoria, mas também para salientar os nomes dos artistas ilustres que nela intervieram, programa que

foi valorizado com um espirituoso desenho devido ao lápis inconfundível de Bordalo Pinheiro.

Carlos Santos.

Cinqüenta anos de teatro, memórias dum ator, p. 101

\section{Introdução}

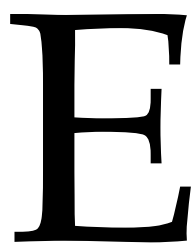

ste artigo é a exposição provisória de algumas conclusões acerca de nossa pesquisa, cuja etapa de trabalho atual se dedica ao paratexto teatral com ênfase nos programas de teatro. ${ }^{2}$ Nosso objetivo vem sendo o de estudar o discurso dos agentes criativos da cena teatral onde possam se expressar para além do espetáculo. Numa primeira etapa de nossa pesquisa, iniciamos uma discussão, que ainda está em curso, sobre o discurso dos autores teatrais acerca de seus próprios textos dramáticos e sua produção em geral, através dos prefácios, posfácios, comentários, advertências, notas e outras manifestações do discurso autoral. Já numa segunda etapa de nossas pesquisas, nos dedicamos, especificamente, ao discurso de outros agentes criativos da cena teatral, cujas ideias são veiculadas nos programas dos espetáculos, projetos

\footnotetext{
1 Felipe Matheus Bachmann Ribeiro é aluno do Curso de Graduação em Letras da UFPR e foi bolsista de IC (2009/2010). Walter Lima Torres Neto é professor de Estudos Teatrais no Curso de Letras e no Programa de Pós Graduação em Letras da UFPR.

2 Esta pesquisa é desenvolvida no âmbito dos estudos sobre a Cultura e Prática teatral: prefácio "modo de usar", idealizada por Walter Lima Torres Neto. E este artigo é fortemente subsidiado pelas pesquisas do aluno Felipe Matheus Bachmann Ribeiro que, no âmbito das suas investigações de Iniciação Cientifica, desenvolveu a pesquisa intitulada: Uma análise dos conteúdos estéticos e mercadológicos dos Programas de Teatro.
}

de montagem, material publicitário entre outros suportes periféricos. ${ }^{3}$

Neste artigo, em especial, procuramos enfatizar o programa de teatro, contextualizando sua condição como objeto de estudo. Assim, procuramos traçar uma breve perspectiva da situação do próprio programa no contexto de nossa cultura e prática teatral no ocidente. Num segundo tempo, esboçamos algumas interpretações parciais, sema total precisão que gostaríamos de demonstrar, acerca de um pequeno acervo de programas de espetáculos nacionais. ${ }^{4}$ Dessa forma, estimamos colaborar com este estudo para uma melhor percepção da função do programa de teatro dentro da dinâmica que envolve os agentes criativos e a coletividade que se beneficia com a produção simbólica gerada pelo teatro.

\section{Breve histórico do programa}

Não se pretende tecer aqui uma genealogia exaustiva do discurso teatral veiculado no programa de espetáculos, uma espécie de arquitexto à maneira de Gérard Genette. ${ }^{5}$ Apesar de nosso intuito ser mais modesto, não podemos avançar em nossas considerações e hipóteses sem

3 Estes suportes ditos periféricos são constituídos, na maioria dos casos, de material publicitário e divulgacional como filipetas, volantes, realeses, flyers dirigidos à imprensa e, sobretudo programas dirigidos ao leitor-espectador.

4 Majoritariamente, o leitor observará que por força das nossas circunstâncias como espectador, a maioria dos 200 programas que possuímos é procedente de MG; SP; RJ; PR e RS. Estimamos, entretanto, que este conjunto, mesmo sem uma representatividade nacional, possa expressar tendências presentes na cena brasileira de forma mais ampla. Nosso objetivo é o de problematizar o objeto programa e secundariamente pensar uma tipologia de programas teatrais nacionais.

5 Gérard Genette, no seu Palimpsestes, Paris, Éditions du Seuil, 1982, pp-7-16, esclarece que o termo arquitexto foi proposto, inicialmente, por Louis Marin, "Pour une théorie du texte parabolique" in: Récit Evangélique, Bibliothèque des Sciences Religieuses, 1974. Nesse sentido, arquitexto designaria um texto de origem de todo discurso possível. 0 arquitexto seria uma espécie de lugar de origem que designaria o meio desde onde se instauraria o próprio discurso. Segundo Genette, esta arquitextualidade englobaria o conjunto de categorias gerais ou transcendentes, tipos de discursos, modos de enunciação, gêneros literários, etc, que advém da singularidade própria de cada texto "lido" como uma literatura ao segundo grau. 
sinalizar ao leitor que, do ponto de vista de sua concepção e sua origem, o programa surge da necessidade de uma comunicação mais eficiente entre aqueles que praticam o teatro, os agentes criativos, e o seu público. Ele é veículo, ele é meio. O programa surge como uma resposta (dos agentes criativos e produtores públicos ou privados da cena, aqueles que detêm os meios de produção) a uma necessidade de aperfeiçoamento do processo de difusão e divulgação de uma apresentação artística que se quer oferecer a uma determinada coletividade. ${ }^{6}$ O programa teatral surgiria assim da evolução - hipótese mais em voga -, numa primeira fase, emancipando-se do cartaz do espetáculo, seu predecessor. A finalidade do cartaz de teatro na sua origem era o de anunciar à sociedade, em espaços públicos e privados, uma programação que possuía dia, horário e local precisos para acontecer. Tratava-se de uma sistematização do lazer.

Diversas parecem ser as fontes com as quais dialogam ou dialogaram os coletivos teatrais brasileiros ao longo do tempo e na atualidade para pensarem a composição do programa de teatro impresso entre nós.

Influenciadas pela cultura e prática teatral de orientação europeia e norte americana, e graças aos diversos ciclos de turnês estrangeiras que nos visitaram no passado, a iniciativa privada e a iniciativa estatal experimentaram, e experimentam ainda, diversos formatos que acabaram por estabelecer certos parâmetros para composição de uma tipologia dos programas de teatro. Dessa forma, é significativo passar em revista ao menos três dessas definições acerca do programa de teatro que nos parecem se relacionar com a sua concepção, sua forma e sua finalidade atualmente.

O programa inglês, por exemplo, teve sua origem certamente no cartaz

6 Nesse sentido, apesar de nos determos aqui mais diretamente sobre os programas de teatro, também se pode constatar uma similaridade tanto em termos de conteúdo quanto em termos de formato e aspectos gráficos relativo aos espetáculos de dança, ópera, circo, música, artes cênicas em geral. que era fixado nas portas dos teatros anunciando os espetáculos da casa. $O$ Oxford Companion to The Theatre traz no mesmo verbete a definição de programa e de cartaz e conjetura a possibilidade de o cartaz ter sido usado como programa, ou seja, distribuído aos espectadores do espetáculo, desde o século XVII: “o primeiro cartaz inglês de que temos conhecimento, e que provavelmente serviu como um programa para ser distribuído em mãos, é do Public Record Office e data de $1672 "{ }^{7}$ Esse programa mais primitivo era o próprio cartaz do espetáculo, dobrado para facilitar o manuseio e então distribuído e/ ou vendido à plateia. No século XIX cartaz e programa se distanciaram e adquiriram configurações próprias. Quando o cartaz aumentou consideravelmente de tamanho, sua dimensão impediu que ele fosse dobrado para servir de programa. Ainda segundo Oxford, "nos anos de 1850, o Olympic Theatre voltou aos programas pequenos para uso dentro do teatro, distribuindo-os, gratuitamente, para os espectadores dos lugares mais caros". Em pouco tempo, o programa popularizouse e passou a ser usado em outros teatros ingleses. A partir desse momento foi selado o divórcio entre o programa e o cartaz, ao menos na Inglaterra, e ambos passaram a trilhar caminhos próprios. Enquanto o cartaz sofria grande influência das escolas de artes gráficas francesas e alemãs e valorizava o aspecto tipográfico, o programa se estabelecia, exclusivamente, como veículo de informações do espetáculo e de publicidade em geral, que apareciam pela primeira vez no ano de 1860, estabilizando-se em 1869 num formato do tipo revista, que perduraria por muitas décadas.

Percebemos as reminiscências dessa distribuição de programas aos espectadores privilegiados em alguns teatros do Brasil durante a década de 1950. Nesses mesmos programas brasileiros observam-se os nomes dos assinantes do teatro. Isso aponta para uma condição do programa que, além

7 Tradução nossa. 
de informativa - e, como veremos adiante, estética - é também social, um rito de distinção, como ensina Bourdieu. ${ }^{8}$

Obedecia à mesma finalidadeenatureza o programa teatral na França. Arthur Pougin no seu Dictionnaire du Théâtre de 1885 é bastante econômico em seu verbete sobre o assunto, enfatizando, entretanto, a ordem da sequência dos números a serem executados pelos artistas, à maneira do que reafirmaria, em 1908, o empresário português Sousa Bastos. Pougin, sem se deter sobre a origem do programa, também chama a atenção para a permanência dos nomes dos artistas relacionados aos nomes das partes, fragmentos, peças e outros títulos desempenhados pelos artistas e que compunham o espetáculo. ${ }^{9}$

Segundo essas duas definições, podese afirmar que a ênfase, a partir da segunda metade do séc. XIX, tanto na França quanto na Inglaterra, esteve no aspecto publicitário, assim como confirmará, em 1908, a definição portuguesa mais abaixo. Se o programa teria evoluído do

8 Acerca da disposição estética do sujeito em relação com o mundo, Pierre Bourdieu afirma que, "no entanto, ela [a disposição estética] é, também, a expressão distintiva de uma posição privilegiada no espaço social, cujo valor distintivo determina-se objetivamente na relação com expressões engendradas a partir de condições diferentes. Como toda espécie de gosto, ela une e separa: sendo o produto dos condicionamentos associados a uma classe particular de condições de existência, ela une todos aqueles que são o produto de condições semelhantes, mas distinguindo-os de todos os outros e a partir daquilo que têm de mais essencial, já que o gosto é o principio de tudo o que se tem, pessoas e coisas, e de tudo o que se é para os outros, daquilo que serve de base para se classificar a si mesmo e pelo qual se é classificado". A distinção, p.56. Nesse sentido, consideramos as listas que constam em certos programas de espetáculos ou placas honoríficas, contendo os nomes dos cidadãosespectadores, assinantes, ou mantenedores da instituição teatral, como este rito de distinção social que atesta a disposição estética de um determinado segmento social. Consequentemente, prestígio e distinção advêm das relações entre o modo como o sujeito classifica a si próprio e como ele se deixa classificar socialmente.

9 No filme Les enfants du paradis de Marcel Carné, de 1945, pode-se observar que no trabalho de reconstituição do ambiente do Boulevard du Temple, ou como ficou mais conhecido o Boulevard du Crime, os "affiches" dos teatros destacam o título dos espetáculos seguidos do nome do artista de destaque associado à encenação. Neste ambiente popular e ruidoso, característico das salas de espetáculos deste local como é descrito no filme, nota-se a ausência do "programa da peça". cartaz de rua, de grandes dimensões, pintado ou mais tarde impresso e colado em locais específicos na cidade, de forma concomitante em todas as principais capitais culturais da Europa, isso não podemos responder no momento. Porém, talvez não seja inexato afirmar que o programa de teatro era distribuído nas salas de espetáculo, sistematicamente, desde a segunda metade do século XIX tanto na França quanto na Inglaterra e possivelmente da mesma forma em grande parte da Europa. Nesse caso, o programa seria uma espécie de versão reduzida da arte gráfica aplicada ao cartaz contendo as especificações do espetáculo e enfatizando o nome dos autores das peças, ensaiadores e diretores bem como dos artistas intérpretes.

No século $X X$, o programa de teatro, nos seus diferentes formatos, independentemente da arte gráfica e do conteúdo do cartaz, era vendido nos espetáculos. Os programas dos ditos Teatros Nacionais, que tendiam a ser ao mesmo tempo "formativos" e informativos, eram distribuídos gratuitamente ou vendidos a preços módicos. Para custear a publicação de seus programas, o dito teatro comercial vendia espaços de publicidade a anunciantes e posteriormente comercializava $o$ programa ao próprio espectador.

Se do ponto de vista do aperfeiçoamento da difusão e comunicação do espetáculo, o programa evoluiu como veículo do formato do cartaz de rua, na virada do século XIX para o XX, do ponto de vista do conteúdo, poderíamos pensar na hipótese de que o programa se manteve fiel à sua matriz principal, isto é, o menu des plaisirs ou dos entretenimentos, oferecidos aos soberanos reais e às suas cortes desde o século XVI. Adviria daí uma das similaridades entre o "menu" teatral com o próprio "menu" gastronômico, como lista detalhada das iguarias que compõem uma refeição. $\mathrm{O}$ programa de um espetáculo ofereceria o detalhamento de um objeto de consumo, de fruição, o "alimento do espírito", dos 
sentidos; da mesma maneira que o menu gastronômico apresenta a lista e a ordem em que se sucedem os pratos a serem oferecidos num banquete. ${ }^{10}$

Finalmente,nestaúltima reflexão, agorade origem portuguesa, propõe-se uma definição bastante singular. De autoria de Sousa Bastos, empresário teatral lusitano de confirmados sucessos comerciais e que tantas vezes visitou o Brasil, o Dicionário do Teatro Português, de 1908, conceituava: "o delineamento de qualquer espetáculo, designando as partes de que se compõe, os artistas que nele tomam parte e a ordem por que é executado, chama programa do espetáculo". Sem nos determos na singularidade das observações do ensaiador e empresário lusitano, pode-se ressaltar duas principais condições. A de que o programa nesse momento era antes de tudo informação, seja sobre o autor e seu repertório a ser apresentado ao espectador, seja sobre o nome dos artistas encarregados da concepção e sua execução. Alia-se ainda a condição de que o programa era ordem ou ordenação da exibição do entretenimento, e como tal deveria ser executado diante do espectador. Como um pequeno contrato, celebrado na compra do ingresso na bilheteria, o programa deveria ser cumprido no decorrer espetáculo. De maneira complementar, Sousa Bastos redigiu ainda um segundo verbete que difere do primeiro, unicamente por estar no plural, "programas", em cuja redação continuava a enfatizar o teor comercial do empreendedorismo teatral, apesar de sua crítica:

A forma de anunciar os espetáculos por
meio de programas é talvez a menos útil,
porque geralmente são mal distribuídos. Na
rua são entregues a torto e a direito, sendo
os garotos os mais contemplados. A muitos
não chegam, e noutros ou embrulham nele
os gêneros ou os rasgam. Não é fácil fazer
um bom programa, que prenda a atenção do

10 As relações entre o teatro e cerimônias sociais envolvendo a gastronomia são um campo bastante vasto onde se destacam, sobremaneira, as atividades teatrais dentro das casas reais europeias. Observe-se que, ao longo da passagem de uma arte de corte para uma arte burguesa, a atividade teatral, o entretenimento, continua a ser apresentado entre refeições. Somente com o advento da autonomização da arte é que se observa uma separação entre ambos. transeunte e o obrigue a ir ver o espetáculo anunciado; mas quando é bem feito, a peça tem tudo a ganhar com ele. Procurar uma forma nova de fazer programas tem toda a vantagem, porque atrai as atenções".

O programa era, então, uma peça publicitária. O curto verbete encerra muito mais uma opinião que, naturalmente, aponta as preocupações do empresárioautor, do que uma definição. Revela-se, portanto uma mentalidade que enfatiza o aspecto comercialdofenômeno teatralnesse início de século XX, e que não difere muito do pensamento existente na atualidade disseminado pela concepção de "produto cultural". Sousa Bastos preocupava-se em fazer uma análise crítica do emprego do programa como material para divulgação e comercialização da programação teatral. Está implícita uma noção, absolutamente moderna, de "público-alvo", que parece nunca ter saído de moda. Como ele nos informa, por um lado, o programa era uma espécie de volante/filipeta, pequeno prospecto entregue fora do teatro aos passantes, na rua, para atraí-los a assistir à peça; por outro lado, haveria a expectativa de que o pequeno impresso chegasse aos estabelecimentos comerciais para serem exibidos, eventualmente fixados nas paredes, e ao serem assim publicizados encontrarem o seu público-alvo, o futuro espectador. O vaticínio de Sousa Bastos é exato quando sugere a aposta em novas formas de fazer programas, isto é, de divulgar sua mercadoria cultural. $\mathrm{O}$ que diria hoje o bem sucedido autor-ensaiador e empresário teatral dos nossos flyers que circulam pela Internet?

\section{De 1952 até 2010: algumas considerações sobre a tipologia do programa de teatro no Brasil}

Contando com um pequeno e heterogêneo corpus de aproximadamente 200programas, editadosentreoanode1952e 2010 de nosso acervo particular, tentaremos lançar as bases para uma reflexão sobre a 
condição do programa de teatro entre nós. As mudanças na forma e no conteúdo em geral ocorrem simultaneamente, e para facilitar o entendimento, dividiremos nossa abordagem em duas partes: uma primeira consagrada aos aspectos formais e outra atinente aos aspectos conteudísticos do programa. $^{11}$

O formato do programa-revista até os anos 1980

Os aspectos tipográficos do programa de teatro permanecem razoavelmente estáveis num período que vai da década de 1950 até o fim dos anos 1980. Percebemos uma constante em todos os programas desse período a que tivemos acesso: o formato característico de uma revista, com um número considerável de páginas e a capa diferindo do miolo, seja no tipo de papel ou na gramatura. Nesse padrão formal a que chamaremos programa do tipo revista ${ }^{12}$ percebemos uma modificação em suas dimensões a partir dos anos 1970. O programa passa de $16 \mathrm{~cm} \times 22 \mathrm{~cm}$ nos anos 1950 e 1960 para $21 \mathrm{~cm} \mathrm{x} 27 \mathrm{~cm}$ a partir do início dos anos 1970.

Outros aspectos formais do programa não apresentam essa rigidez e são alvos de mudanças mais frequentes. $O$ papel passa gradativamente do offset ou papel jornal ao couché. Inicialmente, o couché aparece apenas na capa, em seguida passa a ser usado com mais frequência no miolo; e a partir dos anos 1970 constata-se que a grande maioria dos programas do tipo revista profissionais são impressos em

11 Adotamos este procedimento inspirado no estudo de Gilbert David (2002) sobre os programas de teatro de expressão francesa no Quebéc. Até o momento há poucas pesquisas neste campo, ressaltando-se o estudo de Clóvis Massa: "O paratexto teatral". In: Cena, ano 4, n. 4, UFRGS/Instituto de Artes/Departamento de Arte Dramática, pp. 15-26, ago. 2005. Esse texto foi uma importante colaboração para discussão que estamos encaminhando.

120 termo é utilizado no Oxford Companion to The Theatre: “Em 1869 o St. James's Theatre em Londres começou a distribuir um programa revista num estilo que, com modificações, se mantém popular desde então." (tradução nossa) Não há nenhuma definição de como seria esse estilo, mas o caráter popular do programa-revista inglês também ocorre no Brasil. couché, sendo as páginas das capas em gramatura mais alta.

As impressões coloridas vão aparecendo esparsamente. Já nos anos 1950 alguns programas apresentam a capa e, por vezes a $4^{\circ}$ capa, coloridas. Verificamos uma alternância entre capa colorida e capa preta e branca até o início dos anos 1970, quando as capas passam a ser, majoritariamente, coloridas. Porém, só encontramos o miolo em cores em alguns programas da década de 1980.

A diagramação é um ponto de pouca rigidez durante todo esse período. Não há uma ordem comum na disposição das informações, exceto quanto à ficha técnica do espetáculo que é sempre posicionada nas páginas centrais. Fotos dos artistas e do produtor do espetáculo são muito frequentes, mas não há uma regularidade na forma de sua apresentação. Por vezes, uma imagem ocupa a página inteira, em outras divide o espaço com outros artistas ou com material publicitário. Não obstante, percebemos um fato importante na diagramação dos programas até a década de 1960: o espaço privilegiado que é dado ao produtor e aos atores principais do espetáculo.

A partir do final da década de 1980, alguns experimentos na forma do programa apontam para o novo caminho que seria implementado durante a década seguinte: da diversidade formal em oposição ao padrão revista. O programa do espetáculo ${ }^{13}$ Antígone (1986), ${ }^{14}$ apesar de ainda apresentar um formato similar ao da revista, não tem as mesmas dimensões $(15 \mathrm{~cm} \times 30,5 \mathrm{~cm}$ ao invés de $21 \mathrm{~cm} \times 27$ $\mathrm{cm})$ e, com exceção da capa, não apresenta nenhuma imagem, apenas texto.

Após esse período há uma redução significativa no número de páginas, com

13 As referências dos programas citados no texto serão apresentadas em notas de rodapé da seguinte forma: título, autor e/ou direção, grupo, estado, ano. No corpo do texto será apresentado apenas o título e o ano do espetáculo entre parênteses.

14 Antígone. Sófocles. Antônio Guedes e Helena Varvaki. 0 Studio. RJ. 1986. 
exceção dos espetáculos subsidiados pelo poder público, que ainda utilizam programas similares aos da década de 1980. A redução de páginas e, por conseguinte, da quantidade de informação veiculada, torna cada vez menos frequentes programas do tipo revista, e abre espaço às experimentações gráficas. Aos poucos a padronização vai desaparecendo e podemos dizer que a regularidade formal dos programas é justamente a diversidade de formatos.

Para além da década de 1980, observase que com o tradicional formato revista convivem programas de tipologias muito diversificadas, desde uma simples folha A4 dobrada em duas ou três partes, o que expressa a economia nos meios de produção, até outros exemplares mais sofisticados, como no espetáculo Casa de Laura (2009), ${ }^{15}$ cujo programa é uma pequena bolsa com alguns cartões contendo fotografias e a ficha técnica do espetáculo. Em meio a essa diversidade tipológica, há até mesmo o cartaz, que dobrado serve como programa para o espetáculo Amores Surdos (2006), ${ }^{16}$ exatamente como outrora na Inglaterra até meados do século XIX.

\section{O Conteúdo do programa}

Um fator mercadológico é determinante na mudança de perspectiva pela qual passa o programa ao longo da segunda metade do século XX. Trata-se da quantidade e do tipo de publicidade que é veiculado pelo programa. A ocupação do seu espaço com material publicitário já ocorria na Europa desde meados do século XIX, concomitante com o surgimento do próprio programa como objeto independente do cartaz e com

15 Casa de Laura. Anamaria Nunes. RJ. 2009. Neste mesmo sentido, vale lembrar o programa em formato de cartas de baralho para Um Molière imaginário do Grupo Galpão. MG. 1997. Neste sentido vale lembrar que certas encenações legam junto com o programa um pequeno objeto que literalmente materializa uma metáfora associada ao universo da obra.

16 Amores Surdos. Grace Passô. Rita Clemente. Espanca!. MG. 2006. objetivos específicos de informar mais detalhadamente o espectador acerca do espetáculo.

Do ponto de vista do discurso elaborado pelos agentes criativos e produtivos da cena contemporânea, verifica-se uma autonomia. Das poucas páginas deum prospecto, deum programa, se passa para uma publicação "livresca" mais volumosa e densa, como nos sinaliza Patrice Pavis no seu dicionário acerca dos Teatros Públicos nacionais europeus. Esse princípio está na base de uma ênfase formativa desempenhada, sobretudo pelos programas publicados peloscélebres conjuntos artísticos públicos (TNP, Piccolo Teatro de Milão, Berliner Ensemble, Shauspiller, Bochum, Royal Shakespeare Company, etc.). Esses programas visam para além da informação, a formação do cidadão-espectador, no caso europeu, esclarecendo-o sobre o autor, sobre o conjunto da obra de um determinado autor, sobre o contexto da trama, sobre análises críticas e reflexivas, sobre as razões da encenação e os pressupostos conceituais do diretor, a trajetória da companhia e de seus intérpretes, etc.

O programa de teatro no Brasil, da década de 1950, é muito similar àqueles que já circulavam pelos teatros londrinos na segunda metade do século XIX, em formato de revista, com muitas páginas e recheado de propaganda. Apesar do elevado número de páginas, informações relacionadas diretamente com o espetáculo se resumem à ficha técnica e às fotografias do produtor e dos atores principais.

O principal responsável pelo elevado número de páginas nos programas nos anos 1950 é a publicidade e, em menor grau, a lista de assinantes do teatro, que é creditada no programa. Vejamos como exemplo o programa de Fidélio (1952): ${ }^{17}$ das 44 páginas do programa, 6 creditam os assinantes, 18 são inteiramente ocupadas com material publicitário e todas as outras, excetuando-se apenas a capa, apresentam

17 Fidélio. Bouilly. Carlos Marchese. RJ. 1952. 
algum tipo de publicidade. É de amor que se trata $(1957)^{18}$ traz em seu grosso programa de 76 páginas, 22 ocupadas apenas com publicidade e 74 nas quais a publicidade divide espaço com informações teatrais que não têm relação direta com o espetáculo. Há uma sessão de 8 páginas distribuídas ao longo do programa intitulada curiosidades teatrais, em que o leitor/espectador se depara com informações não pertinentes ao espetáculo, como uma breve biografia de Sarah Bernhardt e de Shakespeare e a história do teatro de revista no Brasil. Ao que parece, são realmente apenas "curiosidades". ${ }^{19}$

Durante a década de 1960, a publicidade continua ocupando boa parte do programa e as fotografias do produtor, do diretor e do elenco - que já apareciam anteriormente, mas de maneira mais discreta - ocupam espaços maiores, às vezes de uma página inteira por fotografia. Em geral, a ordem em que aparecem é: produtor, diretor, atores principais, atores secundários (coadjuvantes), outros profissionais. É também na década de 1960 que começam a surgir os primeiros textos a respeito da peça ou da companhia. Algumas vezes

18 É de amor que se trata. Jean Anouilh. Cayetano Luca de Tena. Os Artistas Unidos. RJ. 1957.

19 Observa-se nesse tipo de curiosidades uma forte reminiscência de publicações do tipo "Almanaque", que abordavam matéria recreativa, humorística, científica, literária e informativa. Vejam-se alguns exemplos no campo teatral: Almanaque do Theatro para o ano de 1907, (organizado por Adhemar Barbosa Romeo, com a colaboração de Arthur Azevedo, Olavo Bilac, Coelho Neto, entre outros). Rio de Janeiro, Typographia da Papelaria Portella, 1906. Ou ainda o célebre Almanaque Guimarães, para o ano de 1885 (organizado sob a direção de Arthur Azevedo), 38o. Ano. Rio de Janeiro, A. Guimarães Editores, 1884. Podendo abranger diversas áreas de interesse, o Almanaque estritamente teatral, de periodicidade variada, trazia informações sobre a atualidade teatral de maneira geral. Em particular, trazia a biografia resumida dos grandes atores e autores, preferencialmente acompanhada de alguma imagem (caricaturas ou clichês); apresentava a temporada dos principais teatros da cidade com suas estreias; anunciava as casas de espetáculos mostrando os preços relativos à distribuição dos lugares na sala de espetáculo; publicava curiosidades teatrais e científicas ou da moda incluindo ainda poesias, ditos populares, pequenas historias, contos, anedotas, entre outras manifestações literárias pontuais. Todo esse conteúdo que estabelecia uma espécie de calendário artístico do entretenimento e do lazer local estava sempre, em alguma medida, associado ao calendário cívico e religioso, não deixando de contemplar as estações do ano. há também uma brevíssima biografia do produtor, do diretor e dos atores principais. Neste período, faz-se apelo à História como disciplina que colabora no processo de legitimação do discurso criativo sugerindo uma perenidade, uma continuidade e a afirmação de um "valor cultural", inerente à montagem teatral, que procura distinguir o dito Teatro de Arte do Teatro Comercial ou de Diversão. ${ }^{20}$

Ainda nessa mesma década podemos constatar uma outra diferença entre o teatro dito de produtor ou independente e o teatro subvencionado pelo poder público. Enquanto o programa de A Megera domada (1964), ${ }^{21}$ encenada pelo Teatro de Comédia do Paraná - grupo teatral do Teatro Guairá, naquela ocasião mantido pelo governo do estado do Paraná - ocupa $21,05 \%$ de suas páginas com publicidade, a taxa ultrapassa $50 \%$ em programas de outras peças do mesmo período como $A$ Vida impressa em dólar (1965), ${ }^{22}$ Liberdade Liberdade (1965), ${ }^{23}$ Antígona (1964) ${ }^{24}$ e Mirandolina (1964). ${ }^{25}$ Também se observa uma diferença referente aos tipos de empresasqueutilizam oespaço publicitário. No programa de A Megera domada há apenas anúncios de órgãos do Governo do Estado do Paraná ou de empresas estatais, ao passo que no programa das outras peças citadas encontramos, majoritariamente, propaganda de empresas aéreas, de moda masculina e feminina, móveis, jóias, bancos

20 Essa dualidade entre Teatro de Arte e Teatro Comercial foi fortemente influenciada pelas iniciativas de Constantin Stanislavski na Rússia e André Antoine na França, na virada do séc. XIX para o XX. Com o naturalismo no teatro, inaugurouse, então, um período de modernização das relações produtivas e, sobretudo, da experiência criativa frente à cena teatral, à ética do ator e consequentemente à relação com o espectador que passa a distinguir um teatro com novas características de linguagem, diverso da produção em série em modelos pré-codificados.

21 A Megera Domada. Shakespeare. Cláudio Correa e Castro. Teatro de Comédia do Paraná. PR. 1964.

22 A Vida impressa em dólar. Clifford Odets. Paulo Afonso Grisolli. RJ. 1965.

23 Liberdade Liberdade. Flávio Rangel e Millôr Fernandes. Flávio Rangel. Grupo Opinião. RJ. 1965.

24 Antigona. Jean Anouilh. Antonio do Cabo. RJ. 1964.

25 Mirandolina. Goldoni. Gianni Rato. Teatro dos sete. RJ. 1964. 
e restaurantes.

No aspecto propriamente artístico, também salta aos olhos a diferença entre esses programas. Com exceção de Mirandolina, os outros três programas, que representam o teatro independente, trazem um pequeno texto sobre a peça e sobre o autor, e no caso de Liberdade Liberdade, também um texto sobre o grupo. No programa de A Megera domada há um estudo um pouco mais detalhado da peça a ser exibida. O texto que abre o programa é de autoria de Bárbara Heliodora, uma autoridade nos estudos shakespearianos. Seguem-se textos de Philomena Gebran Velloso, professora, Millôr Fernandes, tradutor da peça, e Octavio Ferreira do Amaral Neto, superintendente do Teatro Guaíra. Ainda há informações e fotografias da equipe técnica do espetáculo responsável pela cenografia, figurino, música, expressão corporal, ginástica e dicção. A figura do produtor independente está ausente visto que a produção é subvencionada pelo Governo do Estado do Paraná.

Esse tipo de programa característico de espetáculos subsidiados pelo poder público permanece até os dias de hoje. Do mesmo Teatro Guaíra, podemos citar os programas das peças Os Incendiários $(2000)^{26}$ e Esperando Godot (2008), ${ }^{27}$ como programas robustos que se apresentam no formato de revista e se constituem como estudos pormenorizados acerca do espetáculo. Eles denotam, com seus textos assinados por profissionais da área cultural ou por agentes criativos envolvidos na montagem, uma vontade de excelência artística e de se destacar como um Teatro de Arte. Percebe-se que advém daí uma preocupação com a formação cultural do espectador, em oposição ao teatro de puro entretenimento.

Programas que se assemelham aos descritos acima começaram a aparecer em meados da década de 1970. Entre os aspectos que os aproximam citamos mais

26 Os incendiários. Max Frisch. Felipe Hirsch. PR. 2000.

27 Esperando Godot. Samuel Beckett. Flávio Stein. 0 Círculo Núcleo Teatral. PR. 2008. uma vez o formato revista e a preocupação em oferecer ao espectador informações detalhadas sobre a montagem do espetáculo - concepção da encenação, trajetória do autor, currículo dos agentes criativos envolvidos etc. - que tenham o aval de autoridades em assuntos teatrais e/ou culturais. Com a veiculação dessa massa de informações, verifica-se que a publicidade perdeu seu espaço central no programa, assim como a figura do empresário teatral, que passou a ter menor presença nas páginas do programa. Esse fato aponta para a co-habitação entre o teatro dito ainda de empresário, na busca incessante pelo lucro; o teatro de produtor independente, que se arrisca com montagens ditas de "Arte"; o teatro de grupo, em regime de cooperativa, ambos buscando patrocínio privado ou estatal na tentativa de realizarem suas montagens. Ao invés de páginas com publicidades de todos os tipos, a Lei Sarney, ${ }^{28}$ permite que uma grande empresa patrocine o espetáculo e coloque sua logomarca na capa do programa liberando o miolo para veicular informações exclusivas sobre o espetáculo.

Embora as fotografias do diretor e do elenco continuem figurando no programa, é a palavra que adquire maior importância. Os textos se tornam mais elaborados, e a partir dos anos 1980 encontramos programas que configuram verdadeiros estudos a respeito do espetáculo, da mesma forma que os programas de Os Incendiários e Esperando Godot citados anteriormente. O programa de Fedra (1986), ${ }^{29}$ por exemplo, traz em suas 76 páginas: uma cronologia de Racine; um texto do tradutor; um segundo texto do diretor; notas de ensaio elaboradas pelos atores; além de textos de Helio Pellegrino, psicanalista;

28 Em 1986, foi instituída a primeira lei federal de financiamento às atividades artísticas no país, a Lei Sarney. A Lei $n^{\circ} 8.313 / 91$, mais conhecida como Lei Rouanet, consolidou a renúncia fiscal como forma de apoio a projetos culturais e criou o Fundo Nacional da Cultura. Em 1990, o governo Collor suspendeu os benefícios da Lei Sarney, assim como outros incentivos fiscais em vigor. $\mathrm{O}$ mecanismo de apoio às atividades culturais foi restabelecido com a Lei Rouanet, que instituiu o Programa Nacional de Apoio a Cultura (Pronac)". 29 Fedra. Racine. Augusto Boal. RJ. 1986. 
Junito Brandão, especialista em estudos helênicos; Yan Michalski, crítico teatral figuras que por serem expoentes em suas respectivas áreas legitimam a excelência artística do espetáculo ao exprimirem suas opiniões no programa, numa operação de forte distinção cultural.

Com o aparecimento da Lei Sarney, verifica-se uma guinada do ponto vista mercadológico que se reflete na mudança do agente responsável pela produção aqui no sentido estritamente financeiro que atinge o teatro brasileiro. A figura do empresário teatral, detentor do capital, a exemplo de Adaury Dantas, Victor Berbara, Walter Pinto, que dependiam dos valores recolhidos à bilheteria para gerar o lucro, dá lugar ao produtor cultural, proponente de um projeto na área cultural. O pensamento empresarial vai sendo substituído por um processo de produção cada vez mais dependente das leis de incentivo, onde uma empresa ou mais investem parte dos impostosdevidosna produçãodoespetáculo em troca de visibilidade e publicidade de sua imagem institucional. Nesse sentido, trata-se de um novo tipo de produção que não precisa mais se preocupar tanto com o retorno financeiro advindo da bilheteria para pagar a produção, visto que essa deve ser contemplada pelo subsídio fiscal. Dessa maneira, há uma mudança na forma da propaganda veiculada no programa.

Se antes havia um modelo mais tradicional de publicidade em que o leitor-espectador era levado a relacionar a publicidade dos produtos às vedetes do espetáculo, a partir do surgimento das leis de incentivo à cultura, a empresa patrocinadora do espetáculo busca nesse momento se afirmar como agente-parceiro do desenvolvimento cultural do país. Isso se dá a partir de um texto que em geral abre o programa, como podemos constatar no programa de Assimése lhe parece (1980), ${ }^{30} \mathrm{com}$ patrocínio da Shell, onde se lê que a Shell "se identifica com uma das mais emocionantes formas de expressão artística: o teatro".

30 Assim é se Ihe parece. Luigi Pirandello. Paulo Beti. Teatro dos 4. RJ. 1980.
Há uma mudança no formato do programaqueseintensificagradativamente, estabelecendo uma tipologia que, paradoxalmente, se caracteriza pela diversificação. Isso trouxe consequências ao conteúdo do discurso escrito, sendo a principal delas a diminuição de informação que o programa passou a veicular, uma vez que o espaço do programa tornou-se restrito. A imagem supera a palavra escrita como elemento de comunicação.

Umótimo exemploé o programa da peça As três irmãs (1998) ${ }^{31}$ que além de apresentar umformatoforadopadrãorevistatradicional - trata-se de um pedaço de papel, nem A4 nem A3, mas sim um formato vizinho a um prospecto que, estando dobrado em três partes, adquire um formato de postal medindo $15 \mathrm{~cm} \times 21 \mathrm{~cm}$ - se comunica com o leitor-espectador sem utilizar nenhuma palavra, com exceção, é claro, da ficha técnica, elemento sempre presente nos programas. O que "lemos" neste programa são imagens dos atores-personagens em fotografias que, provavelmente, foram feitas para divulgação da peça, com a sugestão de que o ambiente, as atitudes e os figurinos nos remetam ao universo da encenação de Bia Lessa. Percebemos nessa concepção de programa que ressalta o conceitual da direção, odesejo de veicular, excessivamente, a linguagem do próprio espetáculo no objeto programa. Nesse sentido, o programa deixa de ser um veículo apenas de informação ou peça publicitária da montagem. Ele é alçado ao estado de objeto de arte, graças ao seu formato e à sua própria arte gráfica. E minimizando assim sua condição de, unicamente, rastro da concepção do próprio espetáculo, ele reforça o discurso do qual é suporte. O programa passa a dizer tanto sobre a concepção da cena que acaba por direcionar a própria recepção do espectador. Sob esse aspecto, Patrice Pavis alerta para o perigo de tornar o discurso do programa "similar ao discurso da encenação tal como o próprio espectador o recebe e produz" ${ }^{32}$

31 As três irmãs. Anton Tchekhov. Bia Lessa. RJ. 1998.

32 Patrice Pavis. Dicionário de Teatro. São Paulo: Perspectiva, 2005. p. 308. 
Outro exemplo é o programa da peça Suíte 1 (2009), ${ }^{33}$ que mostra um fac-símile de anotações das primeiras impressões que os atores tiveram do texto e outro do desenho do cenário com algumas anotações para a cena de número quatro. Essas informações revelam ao leitor-espectador parte da concepção da cena e da construção da personagem por parte dos atores. Nesse mesmo programa há uma descrição da trajetória da montagem e uma seleção de críticas sobre o espetáculo, elementos que têm a mesma função consagradora daqueles textos de Helio Pellegrino, Junito Brandão e Yan Michalski no programa de Fedra. Neste caso, além da ação de legitimar, historicizando, a trajetória do espetáculo, o programa propõe uma intimidade entre o leitor-espectador e os agentes criativos que expõem seus esboços para as cenas. Pode-se intuir que revelando os "bastidores" da experiência criativa, o laço de adesão entre agentes criativos e espectadores se torna mais forte, possibilitando uma cumplicidade mais efetiva, sobretudo diante de experiências de linguagem mais radicais.

Ainda nessa mesma linha encontramos programas que trazem uma bibliografia, fruto da pesquisa de campo para a escrita do espetáculo. Mais um elemento que também revela a concepção da peça e direciona o leitor-espectador para buscar maiores subsídios sobre o assunto abordado pelo espetáculo. Como exemplos dessa tipologia de programa temos Febre um sintoma cênico (2008) ${ }^{34}$ e O Amargo Santo da Purificação (2009). ${ }^{35}$

Em meio à diversidade tipológica de programas, percebemos certa regularidade em relação ao tipo de informação que alguns programas pretendem dar ao leitorespectador. São programas de companhias consagradas que variam muito as

33 Suíte 1. Philippe Minyana. Márcio Abreu. Companhia Brasileira de Teatro. PR. 2009.

34 Febre - um sintoma cênico. Fernando Kinas. Fernando Kinas. Pausa Companhia de Teatro. PR. 2008.

350 amargo santo da purificação. Criação Coletiva. Tribo de Atuadores Ói Nóis Aqui Traveiz. RS. 2009. informações veiculadas, mas convergem num discurso de afirmação do próprio grupo, geralmente apresentando a história da companhia, seus princípios artísticos, expondo sua ideologia e revelando sua mentalidade diante da experiência criativa. Esse discurso está presente tanto em grupos mais consolidados como A Companhia dos Atores no programa de Autopeças (2008) ${ }^{36}$ e a Tribo de Atuadores Oi Nóis Aqui Traveiz em O Amargo Santo da purificação, quanto em companhias e/ou grupos mais novos, mas já reconhecidos, caso do Grupo Espanca!, que inclui um texto afirmando a identidade do grupo e sua trajetória no programa de sua primeira peça, Por Elise (2006), ${ }^{37}$ quando da temporada de 2006 em Curitiba, um ano após sua estreia.

Entretanto, sobrevivem ainda em pleno século XXI programas nos moldes do século XX. Com a pulga atrás da orelha (2002) ${ }^{38}$ apresenta, além da ficha técnica, apenas fotos do elenco, do diretor e do produtor, de maneira muito similar aos programas dos anos 1950, em formato de revista com destaque para os atores principais, que nesse caso são também atores bastante reconhecidos na televisão brasileira - Herson Capri, Maitê Proença, Edwin Luisi, Rogério Fróes e Françoise Forton - e foto do produtor, que apesar de ser o último a aparecer no programa é a figura com maior destaque.

Como se pode constatar, há uma coexistência de atitudes criativas diversificadas diante de uma mesma dinâmica, isto é, nos procedimentos que consistem na concepção, na apresentação e na divulgação de um espetáculo teatral. Verifica-se uma convivência de experiências criativas diante da prática teatral atual. Neste caso, a tipologia dos programas reflete mentalidades específicas que nos fazem ver de que local social, ideológico, artístico,

36 Autopeças. Companhia dos Atores. RJ. 2008.

37 Por Elise. Grace Passô. Grace Passô. Espanca!. MG. 2006.

38 Com a pulga atrás da orelha. George Feydeau. Gracindo Jr. RJ. 2002. 
empresarial estão se pronunciando esses agentes criativos da cena. Esse conjunto de mentalidades expressa a diversificada e complexa cultura e prática teatral brasileira do ponto de vista da comunicação de um objeto que em certa medida se quer único, artístico, de arte.

\section{O programa de teatro: suas funções e suas ênfases}

Como vimos, o programa de teatro é destinado ao espectador-leitor. Portanto, estamos considerando um grupo alfabetizado com capacidade de efetuar uma leitura consciente do conteúdo veiculado estabelecendo relações com a encenação assistida. Assim sendo, qual seria a função do programa teatral?

Ao concluirmos esse breve artigo, poderíamos idealizar duas funções complementares para uma leitura sistematizada dos programas de teatro. Uma primeira seria a função primária. Essa função seria condicionante e adviria da própria natureza do objeto programa, visto que se o programa não a cumprir não poderemos caracterizálo como tal. Nesse sentido, todos os programas apresentariam um compromisso com um conjunto de informações. Sejam essas informações gráfico-visuais ou escritas, elas são referentes aos créditos artísticos e técnicos atribuídos aos agentes criativos e produtivos mobilizados para a realização da apresentação pública anunciada. Complementam essas informações o enunciado da obra a ser difundida e exibida, isto é, seu título, juntamente com sua periodicidade, horário e local específico da exibição.

A principal característica do programa, considerando sua gênese a partir do cartaz de rua, seria o seu compromisso com a seleção e exibição do conjunto de informações diversas sobre a concepção e a apresentação artística ou o universo por onde essa criação transita. Trata-se, portanto de uma ênfase informativa.

Para além desta função primária esclarecendo ao espectador sobre a ficha técnica, estampando, por vezes, o resumo da ação, a ênfase informativa está calcada numa mediação entre palco e plateia. É natural que percebamos outras ênfases junto aos programas de teatro que variam de acordo com a época, os coletivos teatrais, o sistema de produção, entre outros fatores comunicacionais e de mercado cultural. Podemos tentar entender melhor a natureza da prática teatral segundo os programas teatrais se nos perguntarmos acerca da ênfase que eles estimam dar ao se dirigirem ao espectador.

Complementandoessa primeirafunção, poderíamos adicionar uma segunda, função secundária, que se caracterizaria pelo conjunto de informações passíveis de serem veiculadas promovendo uma diversificação que acabaria por revelar os objetivos específicos e as ênfases dos mais diversos tipos de experiências criativas promovidas pelos artistas. Essa atitude gera uma inumerável tipologia de programas.

O programa via de regra afirma uma identidade do coletivo teatral que o origina, ou do próprio espetáculo a ser exibido, no caso de uma apresentação esporádica com um elenco ocasional. Traduzindo as relações de uma política cultural entre as instituições e a sociedade, seja no âmbito da iniciativa privada ou da iniciativa pública, o programa revela uma identidade. Essa identidade sendo individual, coletiva ou de classe, revelaria tanto os princípios do coletivo criativo e do espetáculo, quanto reafirmaria a trajetória dos agentes criativos inscrita no âmbito da sua cidade, do seu estado ou do seu país.

O programa regula e revela uma experiência criativa que se quer compartilhada, eexpõeuma mentalidade sobre a dinâmica de trabalho construindo 
uma cultura e prática teatral que espera ganhar a adesão do público. Como na atualidade há espetáculos que não nos contam, necessariamente, uma história, mas apresentam uma sucessão de ações por meio de partituras vocais e corporais, experimentos cênicos que negam a representação, convocando a cumplicidade do espectador por outros sentidos, o programa - em sua função secundária - é um importante mediador da proposta estético-cultural adotada por esses agentes criativos da cena.

Não mais condicionado por uma função primária, cuja ênfase é informativa, o programa de teatro se revela como relato de trabalho ou como exposição teórica da proposta do coletivo teatral. O programa também se apresenta como um memorial descritivo e analítico das etapas de trabalho que originaram a cena. Desta maneira, o programa busca a adesão do espectador com a finalidade de estabelecer laços de fidelização.

As transformações pelas quais passou o programa de teatro durante esse meio século estabelecem um pacto estético-cultural, permanentemente dinâmico, entre o público e o espetáculo. O programa, por vezes, é alçado ao patamar de obra de arte, por conta da sua autonomia e sofisticação em termos de linguagem gráfica e visual, passando a possuir um valor autônomo em detrimento do espetáculo que ele deveria divulgar. Essa publicação, contudo, não deixa de ser a fiel depositária, a fonte, o documento sujeito à reflexão a posteriori, por ser um vestígio do instantâneo que constitui a própria história do espetáculo. A redação do programa investe na formação, no aperfeiçoamento e, por conseguinte, no estreitamento das relações com seu leitor-espectador. Ao pretender ser suporte para uma difusão e fidelização de uma produção cultural imaterial, simbólica, o programa continua sendo um vestígio, um traço memorialístico do espetáculo teatral.

\section{Referências bibliográficas}

BOURDIEU, Pierre. A distinção: critica social do julgamento. Porto Alegre: Editora Zouk/EDUSP, 2008.

CORVIN, Michel (Org.). Dictionnaire Encyclopédique du Théâtre. Paris: Larrousse-Bordas, 1998.

COSTA, Marta de Moraes da. Palcos e Jornais: representações do teatro em Curitiba entre 1900 e 1930. Curitiba: Editora UFPR, 2009.

DAVID, Gilbert. Théatres au programme: panorama des programmes de thêâtre de langue française à Montréal aux XXème siècle. Montreal: CETUQ / BN Québec, 2002.

GENETTE, Gérard . Seuils. Paris: Editions du Seuil, 1987.

GENETTE, Gérard. Palimpseste. Paris: Editions du Seuil, 1982.

HARTNOLL, Phyllis (Ed.). The Oxford companion to the theatre. Oxford: Oxford University Press, 1983.

MASSA, Clóvis. O paratexto teatral. In: Cena, ano 4, n. 4, UFRGS/Instituto de Artes/Departamento de Arte Dramática, pp. 15-26, ago. 2005.

PAVIS, Patrice. Dictionnaire du Théatre. Paris: Dunod, 1996.

POUGIN, Arthur. Dictionnaire du Théâtre (Les Introuvables. Reedição do original de 1885). Paris: Editions d'Aujourd'hui, 1985.

SANTOS, Carlos. Cinqüenta anos de teatro, memórias de um ator. Lisboa, Typografia da Empresa Nacional de Publicidade, 1950.

SOUSA BASTOS, Antonio de. Dicionário do Teatro Português ( $1^{\mathrm{a}}$ edição fac-similada conforme a edição de 1908). Lisboa: Arquimedes Livros, 2006. 
(3) 